\title{
To print or not to print
}

\section{Or the publisher's dilemma how to present a growing complexity of scientific knowledge to clinicians, helping them to improve their daily care for their patients}

Wolfgang Hilbe $\cdot$ Rupert Bartsch $\cdot$ Waltraud Radlherr

Published online: 3 March 2017

C Springer-Verlag Wien 2017

Ten years ago, in spring 2007 a noble lady wearing a queenly looking hat invited me (WH) to start a new printed journal on hematology and oncology with a focus on the German-speaking community. The well-known publisher Springer Company intended to expand in that field of medicine. Certainly, it was a distinguished honor being selected for such a project. But, analyzing the opportunities and potential draw-backs of such a project, I came to the conclusion: "hands off!". Considering the small number of Austrian hematologists and medical oncologists, the potential of authors or reviewers would have been fully exhausted within the first three issues.

As a clinician and-at that time as a young oncologist-I was full of ideals but also confronted with an overloaded working day. Indeed, there was no time for reading one of those wonderful and comprehensive reviews citing hundreds of references or to have the chance for maintaining an overview by studying all the relevant original reports. What I really needed was a short and focused summary of the most burning topics giving me the opportunity to gain a qualified overview of critical issues and developments. After having defined these criteria, an alter-

\section{W. Hilbe, MD ( $\varangle)$}

Department of Oncology, Hematology and Palliative Care, Wilhelminenspital, Montlearstraße 37, 1160 Vienna, Austria wolfgang.hilbe@meduniwien.ac.at

\section{R. Bartsch, MD}

Department of Medicine 1, Clinical Division of Oncology and Comprehensive Cancer Center, Medical University of Vienna, Waehringer Guertel 18-20, 1090 Vienna, Austria rupert.bartsch@meduniwien.ac.at

W. Radlherr

Speckkarstraße 27, 6068 Mils, Austria native form of journal was proposed to the publisher: this new magazine should be set up on an international level, communicate in English and offer a platform for hematologists and oncologists all around the world. Peer-reviewed publications, short reviews focusing on hot topics, and concise congress reports updating our knowledge should be presented. By covering all these items, the Magazine of European Medical Oncology (memo) was created. And now, more than 400 peer-reviewed publications later, written by more than 1000 authors and co-authors, critically reviewed by more than 700 experts, including thousands of e-mails, memo has come of age. The adventurous trip of the memo team has reached its first destination and everyone is now ready to celebrate the fact that memo has established its place within the oncology world during the first ten years of its existence.

In 2016, we experienced a full-paper down-load rate of 10,000 downloads around the world, proving that our concept is highly appreciated by the community. This success is certainly also due to the presentation of an electronic version of memo. Nevertheless, writing a paper accurately, reviewing the text critically, setting the types professionally, and designing a printable page are a complex process, finally leading to a product, which is appreciated by the readers. Being confronted with a plethora of industry-sponsored media and numerous publications written by marketing experts, the availability of an independent interpretation of data has gained significant value.

The memo family has grown up, so many authors and reviewers have come together, presenting their knowledge or conveying their critical opinion. Thus, many young oncologists have seized the opportunity to present their first publication in our peer-reviewed journal and have learned how to communicate within 
the scientific community. A jubilee is the time to look back and to thank all those, who have supported our initiative so consequently and who have come along with us all the way. It is, however, also the time to look ahead. A speedily changing environment will also challenge traditional ways of presenting and using knowledge. But finally, an independent and professional attitude towards the accumulation of complex amounts of data is essential to translate scientific findings into clinically applicable practice, thereby, improving patients' care. And still, as already stated in 2007 "For the next years we will keep on giving our best, making memo a leading journal in Europe"; "yes we can!".

Conflict of interest W. Hilbe, R. Bartsch, and W. Radlherr declare that they have no competing interests.
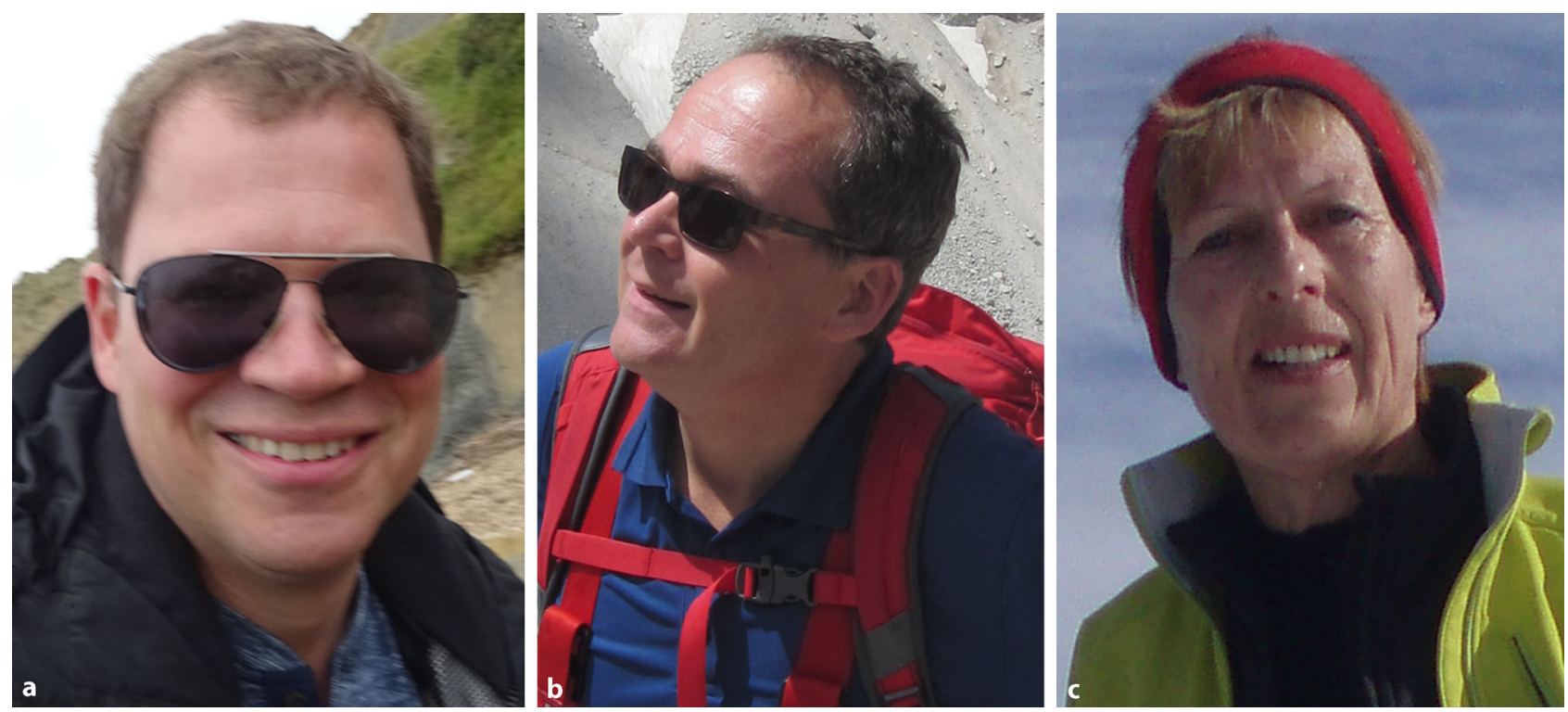

The well-attuned team of memo. a Rupert Bartsch-the academic spearhead. $\mathbf{b}$ Wolfgang Hilbe -the optimistic pathfinder. c Waltraud Radlherr - the master of memo's web 